\title{
Klinik Candida lusitaniae Kökenlerinin Amfoterisin B'ye İn Vitro Duyarllığı: Çok Merkezli Çalışma
}

\author{
Ayşe KALKANCI*, Kenan HIZEL**, Ali FOUAD*, Nilgün ÇERIKÇİĞLLU***, Işın AKYAR****, \\ Rukiye BERKEM*****, Zayre ERTURAN******, Semra KUŞTIMUR* \\ * Gazi Üniversitesi Tıp Fakültesi, Tibbi Mikrobiyoloji Anabilim Dalı \\ ** Gazi Üniversitesi Tip Fakültesi, Enfeksiyon Hastalıkları Anabilim Dalı \\ *** Marmara Üniversitesi Tip Fakültesi, Tibbi Mikrobiyoloji Anabilim Dalı \\ ***** Acıbadem Üniversitesi Tip Fakültesi, Tıbbi Mikrobiyoloji Anabilim Dalı \\ ***** Sağllk Bakanlığı Ankara Ĕ̆gitim ve Araştırma Hastanesi, Tıbbi Mikrobiyoloji Kliniği \\ ******* İstanbul Üniversitesi İstanbul Tip Fakültesi, Tibbi Mikrobiyoloji Anabilim Dall
}

\section{ÖZET}

\begin{abstract}
Amaç: Amfoterisin B (AmB) invazif mantar enfeksiyonlarının tedavisinde kullanilan poliyen grubu bir antifungaldir. Klinikte Candida lusitaniae ile oluşan mantar enfeksiyonlarının AmB tedavisine yanıt vermediğ i, in vitro duyarlıllk testlerinde kökenlerin dirençli bulunduğu bildirilmiştir. AmB ile karşılaşma sonrasında minimum inhibitör konsantrasyon (MIK) de ğerlerinin yükseldiği ile ilgili çalışmalar bulunduğu gibi, tersine kökenlerin bütünüyle AmB'ye duyarlı olduğunu bildiren çalışmalar da bulunmaktadır. $B u$ çalışmanin amacl, C. lusitaniae kökenlerinin AmB duyarlılığlnin gösterilmesidir.
\end{abstract}

Gereç ve Yöntem: Bu çalıșma kapsamında dört ayrı merkezden tür düzeyinde tanımlanmış 60 C. lusitaniae kökeni toplanmıştır. Toplanan kökenlerin tür düzeyinde tanımlanmaları üc merkezde klasik mikolojik yöntemler ile yapılmıştır. Acıbadem Üniversitesi Tıp Fakültesi, Tibbi Mikrobiyoloji Anabilim Dalı'nda tür tanımı MALDI-TOF cihazı ile gerçekleştirilmiştir. Gazi Üniversitesi Tip Fakültesi, Tıbbi Mikrobiyoloji Anabilim Dalı'nda kökenlere in vitro duyarlılık testi uygulanmıştır. Clinical and Laboratory Standards Institute (CLSI) mikrodilüsyon yöntemi ve E-test yöntemi ile MiK değerleri elde edilmiştir.

Bulgular: Mikrodiliusyon yönteminden elde edilen MIK değerleri-

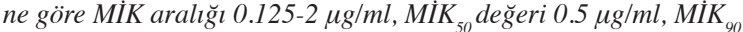
değeri $1 \mu \mathrm{g} / \mathrm{ml}$ olarak hesaplanmusttr. E-test sonucunda elde edilen

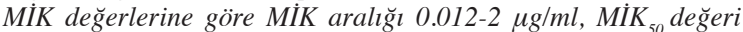
$0.25 \mu \mathrm{g} / \mathrm{ml}$, MiK $K_{90}$ değeri $0.75 \mu \mathrm{g} / \mathrm{ml}$ olarak hesaplanmıştır. Mikrodiliusyon yöntemi sonuçlarına göre 60 kökenden 8 tanesinden (\%13), E-test sonuçlarina göre 6 tanesinden $(\% 10) \geq 1 \mu \mathrm{g} / \mathrm{ml}$ MiK değerleri elde edilmiştir. Mikrodilüsyon ile iki, E-test ile bir köken için MiK değeri $2 \mu \mathrm{g} / \mathrm{ml}$ olarak bulunmuştur.

Sonuç: Bu in vitro çalışma, AmB'ye intrensek dirençli olduğu ileri sürülen $C$. lusitaniae kökenlerinin in vitro duyarlı olduğunu, bu nedenle C. lusitaniae enfeksiyonlarında AmB kullanımı seçeneğinin yeniden gözden geçirilmesi gerektiğini ortaya çıkarmışıtır. Sonuçlarımı in vivo modeller ile desteklendiğinde daha kesin yargılara varilabilecektir.

Anahtar kelimeler: Amfoterisin B, Candida lusitaniae, duyarlllı

\section{SUMMARY}

In Vitro Susceptibility of Clinical Candida lusitaniae Isolates Against Amphotericin B: A Multicenter Study

Aim: Amphotericin B $(A m B)$ is a wide spectrum antifungal drug which is used for the treatment of invasive fungal infections. Among the fungal pathogens, Candida lusitaniae has been reported to be resistant to AmB in-vitro. Therefore, AmB is not recommended for the treatment of $C$. lusitaniae infections. There are conflicting data on this subject in the literature. Some of the studies showed that minimal inhibitory concentration (MIC) values increased following exposure to AmB, while the others indicated that all C. lusitaniae were fully susceptible to $A m B$. The aim of the present study was to evaluate the AmB susceptibility of the C. lusitaniae strains.

Materials and Methods: The study included 60 C. lusitaniae strains obtained from four different teaching hospitals in Turkey. The strains were identified at species level by using conventional methods in three of the centers and by MALDI-TOF method in one center. In vitro susceptibility testing was performed by E-test and Clinical and Laboratory Standards Institute (CLSI) reference microdilution method.

Results: AmB MIC range was found as 0.125-2 $\mu \mathrm{g} / \mathrm{ml}, M C_{50}$ value was $0.5 \mu \mathrm{g} / \mathrm{ml}$, and $\mathrm{MIC}_{90}$ value was $1 \mu \mathrm{g} / \mathrm{ml}$ by microdilution method. MIC range, $M I C_{50}$, and $M I C_{90}$ values were $0.012-2 \mu \mathrm{g} / \mathrm{ml}$, $0.25 \mu \mathrm{g} / \mathrm{ml}$, and $0.75 \mu \mathrm{g} / \mathrm{ml}$ by E-test method, respectively. The number of isolates with $M I C \geq 1 \mu \mathrm{g} / \mathrm{ml}$ were $8(13 \%)$, and $6(10 \%)$, for microdilution and E-test methods, respectively. MIC value was $2 \mu \mathrm{g} / \mathrm{ml}$ for two strains by microdilution method, and one strain by E-test method.

Conclusion: Our results showed that C. lusitaniae strains which were considered as intrinsically resistant, were susceptible to AmB. Although, more definite conclusions achieved by in vivo studies are required, this study indicated that $A m B$ could be a good choice for the treatment of infections caused by C. lusitaniae.

Alındı̆̆ı tarih: 22.04 .2015

Kabul tarihi: 02.11.2015

Yazışma adresleri: Ayşe Kalkancı, Gazi Üniversitesi Tıp Fakültesi, Tıbbi Mikrobiyoloji Anabilim Dalı, Beşevler, Ankara Tel: (0312) 2024629 e-posta: kalkanci@gazi.edu.tr

${ }^{\S}$ Bu araştırma, 3-7 Kasım 2012 tarihlerinde düzenlenen 35. Türk Mikrobiyoloji Kongresi’nde poster olarak sunulmuştur. 


\section{GíRIŞ}

Amfoterisin B (AmB) 1950'li yıllarda Venezuella'nın Orinoco River bölgesinden toplanan toprak aktinomiçeti Streptomyces nodosus'un bir kökeninden izole edilmiş poliyen grubu doğal bir antibiyotiktir. İnvazif mantar enfeksiyonlarının tedavisinde 1960 'dan beri “altın standart" olarak kullanılmaktadır. Membrandaki ergosterole bağlanarak por görevi yapacak oligodendogramların oluşmasına neden olmaktadır. Porlar membran geçirgenliğini değiştirerek, hücre içinden katyonların ve nükleoprotein gibi makromoleküllerin hücre dişına kaçışına ve hücre ölümüne neden olmaktadır ${ }^{(1,2)}$.

Candida lusitaniae 1970 yılında tanımlanmış, haploid bir maya mantarıdır. Tam bir eşeyli üreme döngüsü bulunmaktadır. Fenotipik "switching” sonrası 104 hücreden birinde AmB direnci geliştiği bildirilmiştir ${ }^{(3)}$. C. lusitaniae için AmB direncinin gelişmesinde olası mekanizma membrandaki ergosterol yapısının bozulması, alternatif ergosterol yapımı, biyosentezindeki azalmaya bağlı olarak ergosterol miktarının azalması olabilir ${ }^{(4)}$. AmB direnci hem intrensek hem de sekonder olabilir. Direncin gelişimi ile ilgili bilgimiz azdır. Ergosterol biyosentezinde görevli enzimleri kodlayan genler $E R G$ genleridir. Flukonazol direncinin gelişmesinde en önemli mekanizma olarak ERG11 genindeki mutasyonlar tanımlanmıştır. Benzer şekilde AmB direnci için de ERG3 ve ERG6 genlerindeki mutasyonların AmB direnci ile ilgili olduğu bildirilmiştir ${ }^{(3,5)}$.

\section{C. lusitaniae enfeksiyonlarının tedavisinde AmB} kullanılmasının tedavi başarısızlığg ile sonuçlandı ğını bildiren yayınlar bulunmaktadi ${ }^{\mathrm{r}(6,7)}$. İn vitro duyarlılık çalışmalarında da AmB'nin yüksek minimum inhibitör konsantrasyon (MIK) değerlerinin elde edildiği bildirilmiştir ${ }^{(8,9)}$. Ayrıca AmB ile karşılaştıktan sonra bazı C . lusitaniae kökenlerinde MİK değerlerinin öncekilere göre yükseldiğini bildiren yayınlar da bulunmakta$\mathrm{d}_{1} \mathrm{r}^{(10)}$. Bu bilgilere dayanarak $C$. Iusitaniae AmB'ye dirençli bir köken olarak listelenmektedir. Ancak, C. krusei ve flukonazol örneğinde olduğu gibi in vitro duyarlılık testlerinde kesin bir direnç elde edilmemektedir. Bu durumda C. lusitaniae enfeksiyonlarının AmB ile tedavi edilebilmeleri sorusu net olarak evet veya hayır diye yanıtlandırılmış değildir. $\mathrm{Bu}$ nedenle in vitro duyarlılık çalışmalarının yapılmasına devam edilmektedir.

Bu çalışmada, farklı merkezlerden toplanan toplam 60 C. lusitaniae kökeninin referans mikrodilüsyon yöntemi ve E-test yöntemi ile AmB'ye in vitro olarak duyarlılığının araştırılması amaçlanmıştır.

\section{GEREÇ ve YÖNTEM}

Mantar kökenleri: Çalışma kapsamında Marmara Üniversitesi Tıp Fakültesi, Acıbadem Üniversitesi Tıp Fakültesi, İstanbul Üniversitesi İstanbul Tip Fakültesi, Tibbi Mikrobiyoloji Anabilim Dalları ile Sağlık Bakanlığı, Ankara Eğitim Araştırma Hastanesi, Mikrobiyoloji Kliniği olmak üzere dört ayrı merkezden toplam 60 C. lusitaniae kökeni toplanmıştır. Toplanan kökenlerin tür düzeyinde tanımlanmaları üç merkezde klasik mikolojik yöntemler ile yapılmıştır. Bunun için germ tüp negatif kökenler mısır unutween 80 agarda maya morfolojileri açısından incelenmiştir. Sonrasında karbonhidratların asimilasyonu temeline dayanan ID32C maya tanımlama kiti (bioMérieux) kullanılmıştır. Acıbadem Üniversitesi Tıp Fakültesi, Tıbbi Mikrobiyoloji Anabilim Dalı'nda kökenlerin tür tanımı MALDITOF cihazı ile gerçekleştirilmiştir.

Antifungal duyarlılı testleri: Tür düzeyinde tanımlanan kökenler Gazi Üniversitesi Tıp Fakültesi, Tıbbi Mikrobiyoloji Anabilim Dalı'na gönderilmiştir. Deney gününe kadar distile su içinde koloni süspansiyonları hazırlanan kökenler 
$-80^{\circ} \mathrm{C}^{\prime}$ de bekletilmiştir. Duyarlılık testi öncesinde kökenler iki kez pasajlanmış ve Saboraud Dekstroz Agar'da (SDA) yapılan 24 saatlik ikinci pasajlar duyarlılık testi için kullanılmıştır. C. lusitaniae kökenlerinin AmB'ye duyarlılıklar1 mikrodilisyon ve E-test yöntemleri ile araşt1rılmıştır. Clinical Laboratory Standarts Institute (CLSI) önerilerine uygun L-glutaminli RPMI 1640 kullanarak referans mikrodilüsyon yöntemi uygulanmıştır. AmB konsantrasyon 0.03-16 $\mu \mathrm{g} / \mathrm{ml}$ aralığında belirlenmiştir. MíK değerleri 24 saat inkübasyon sonrasında değerlendirilmiş, kaydedilmiştir ${ }^{(11)}$. E-test yöntemi için \%1.5 agar ve $\% 2$ glukoz eklenmiş antibiyotik medyum 3 (AM3) kullanılmıştır ${ }^{(12)}$. C. lusitaniae kültüründen $0.5 \mathrm{Mc}$ Farland bulanıklığında süspansiyonlar hazırlanmış ve eküvyon aracılığıyla AM3 besiyerinin yüzeyine eşit dağılımlı bir şekilde yayılıp AmB E-test şeritleri yerleştirilmiştir. Plakların 24 saat inkübasyonundan sonra sonuçlar değerlendirilmiş ve MİK değerleri kaydedilmiştir. Kalite kontrol kökenleri olarak Candida albicans ATCC 10231 ve Candida krusei ATCC 6258 kullanılmıştır.

\section{BULGULAR}

Mikrodilüsyon yönteminden elde edilen MİK

Tablo 1. Mikrodilüsyon ve E-test yöntemlerinden 24 saatte elde edilen MİK aralığı, MIK $_{50}$ ve MIIK $_{90}$ değerleri.

\begin{tabular}{lcc}
\hline & CLSI mikrodilüsyon & E-test \\
\hline Mí aralı̆ $(\mu \mathrm{g} / \mathrm{ml})$ & $0.125-2$ & $0.012-2$ \\
MiK $_{50}(\mu \mathrm{g} / \mathrm{ml})$ & 0.5 & 0.25 \\
MIK $_{90}(\mu \mathrm{g} / \mathrm{ml})$ & 1 & 0.75 \\
\hline
\end{tabular}

değerlerine göre AmB için MİK aralığ1 0.125-2 $\mu \mathrm{g} / \mathrm{ml}$, MİK $_{50}$ değeri $0.5 \mu \mathrm{g} / \mathrm{ml}$, MİK $_{90}$ değeri 1 $\mu \mathrm{g} / \mathrm{ml}$ olarak hesaplanmıştır. E-test sonucunda elde edilen MIK değerlerine göre $\mathrm{AmB}$ için MíK aralığ $10.012-2 \mu \mathrm{g} / \mathrm{ml}$, MIK $_{50}$ değeri 0.25 $\mu \mathrm{g} / \mathrm{ml}$, MİK $_{90}$ değeri $0.75 \mu \mathrm{g} / \mathrm{ml}(1 \mu \mathrm{g} / \mathrm{ml})$ olarak hesaplanmıştır (Tablo 1). AmB'ye in vitro dirençli olduğu bildirilen $C$. lusitaniae kökenlerinin AmB için MíK düzeyleri düşük bulunmuştur. Çok az sayıda in vitro dirençli köken elde edilmiştir. Mikrodilüsyon yöntemi sonuçlarına göre 60 kökenden 8'inden (\%13), E-test sonuçlarına göre 6'sından (\%10) $1 \mu \mathrm{g} / \mathrm{ml}$ ve üzerinde MİK değerleri elde edilmiştir. E-test için 0.38 $\mu \mathrm{g} / \mathrm{ml}$ değeri direnç sınırı olarak kabul edilir ise 9 köken (\% 15) dirençli olarak ayrılmıştır. E-test için sınır değerin $1 \mu \mathrm{g} / \mathrm{ml}$ 'den $0.38 \mu \mathrm{g} / \mathrm{ml}$ 'ye indirilmesi durumunda 3 köken daha dirençli gruba eklenmiştir. Mikrodilüsyon ile iki kökenin, E-test ile bir kökenin MİK değeri $2 \mu \mathrm{g} / \mathrm{ml}$ olarak bulunmuştur.

CLSI yöntemi referans alındığında E-test için; çok büyük hata (dirençli kökenin duyarlı bulunması) ve büyük hata (duyarlı kökenin dirençli bulunması) oranları hesaplanmıştır ${ }^{(13)}$. Küçük hata (herhangi bir yöntemle orta duyarlı bulunan kökenin diğer yöntemle duyarlı veya dirençli bulunması) AmB için “orta duyarlı olma" tanımlaması bulunmadığı için hesaplanmamıştır. Hesaplama mikrodilüsyon için sınır değer 1 ve 2 $\mu \mathrm{g} / \mathrm{ml}$, E-test için $0.38,1,2 \mu \mathrm{g} / \mathrm{ml}$ olarak kabul edildiğinde olmak üzere ayrı ayrı hesaplanmış ve tablo hâline getirilmiştir (Tablo 2). Tablodan

Tablo 2. Mikrodilüsyon ve E-test sınır değerlerine göre E-test için çok büyük hata, büyük hata oranları.

\begin{tabular}{|c|c|c|c|c|c|c|c|}
\hline \multirow[b]{2}{*}{ Dirençli köken n (\%) } & \multicolumn{7}{|c|}{ E-test } \\
\hline & & \multicolumn{2}{|c|}{$9(\% 15)$} & \multicolumn{2}{|c|}{$6(\% 10)$} & \multicolumn{2}{|c|}{$-(\% 10)$} \\
\hline Direnç sınır değeri & & \multicolumn{2}{|c|}{$0.38 \mu \mathrm{g} / \mathrm{ml}$} & \multicolumn{2}{|c|}{$1 \mu \mathrm{g} / \mathrm{ml}$} & \multicolumn{2}{|c|}{$2 \mu \mathrm{g} / \mathrm{ml}$} \\
\hline Hata tanımı & $\mu \mathrm{g} / \mathrm{ml}$ & ÇBH* & $\mathbf{B H} * *$ & ÇBH* & $\mathbf{B H} * *$ & ÇBH* & $\mathbf{B H} \mathbf{H}^{* *}$ \\
\hline $\begin{array}{l}\text { Mikrodilüsyon direnç oranları ve sınır değerler } \\
\quad 8\left(\begin{array}{l}\% \\
13\end{array}\right) \\
\quad-(\% 0)\end{array}$ & $\begin{array}{l}1 \\
2\end{array}$ & - & $\begin{array}{c}1(\% 2) \\
7(\% 12)\end{array}$ & $\begin{array}{c}2(\% 3) \\
-\end{array}$ & $4(\% 7)$ & $\begin{array}{c}7(\% 12) \\
1(\% 2)\end{array}$ & - \\
\hline
\end{tabular}

*: ÇBH; Çok büyük hata, BH; Büyük hata. 
da anlaşılacağı üzere, CLSI mikrodilüsyon yönteminde sınır değerin $1 \mu \mathrm{g} / \mathrm{ml}$ alındığ E-test sınır değeri $0.38 \mu \mathrm{g} / \mathrm{ml}$ ise en iyi uyumluluk elde edilmiştir. Bu durumda E-test çok büyük hata yapmamıştır. Bir kökende (\%2) büyük hata yapmıştır. Mikrodilüsyon testinde sınır değer $2 \mu \mathrm{g} / \mathrm{ml}$ olarak kabul edildi ise, E-test sınır değeri de $2 \mu \mathrm{g} / \mathrm{ml}$ olarak alındığında iki test arasında en iyi uyumluluk elde edilmiştir. $\mathrm{Bu}$ koşulda, E-test 1 kökende (\% 2) çok büyük hata yapmiştır.

\section{TARTIŞMA}

Kandidemi olgularının epidemiyolojik analizlerinin yapıldı̆̆ 1 çalışmalara bakıldı̆̆ında C. albicans dişında kalan etkenler arasında, C. lusitaniae enfeksiyonlarının C. glabrata, $C$. parapsilosis, $C$. tropicalis ve $C$. krusei'den sonra beşinci sıklıkta görüldügüü anlaşılmaktadir ${ }^{(14)}$. Çalışmalarda değişik oranlar verilmiş ancak sıralama genellikle değişmemiştir. Pediyatrik grupta $C$. lusitaniae ile oluşan kandidemilerde en yüksek mortalite oranı bildirilmiştir ${ }^{(15,16)}$. Klinikte $C$. lusitaniae enfeksiyonları ile karşılaşılması olasılığı çok da düşük değildir. Bu nedenle tedavi seçeneklerinin genişletilmesinin yararlı sonuçları olabilir.

C. lusitaniae' da AmB'ye in vitro direncin saptanmasıyla ilgili sorunlar bulunmaktadır. Henüz direnç sınır değerleri saptanmamıştır. İn vitro çalışmalarda dar MİK aralığı elde edilmekte ve dirençli kökenler ayırt edilememektedir. Kullanılan besiyerlerine \%2 glukoz eklenmesinin dirençli kökenlerin ayırımına yardım ettiğ $i^{(12)}$, E-test için AM3 besiyerinin kullanılmasının mikrokoloni oluşumunu azalttığ ${ }_{1}$ bildirilmiştir ${ }^{(9)}$. Çalışmamızda bu öneriler doğrultusunda \%2 glukoz eklenmiş RPMI ve AM3 besiyerleri kullanılmış ve sınır değere göre değişmek üzere, mikrodilüsyon için \%13 veya \%3, E-test için $\% 15$ veya $\% 10$ oranında dirençli köken ayrılabilmiştir.
$\mathrm{Bu}$ güne kadar yapılmış in vitro çalışmaların çoğunda AmB direnci gösterilememiştir ${ }^{(4,12,17-19)}$. $\mathrm{Bu}$ çalışmalarda, kökenlerin tamamından çok düşük MİK değerleri elde edilmiş ve kökenler duyarlı bulunmuştur. Örneğin 23 kökenin incelendiği bir çalışmada, mikrodilüsyon, E-test ve disk difüzyon yöntemleri kullanılmış, en düşük MIK değerleri E-test ile elde edilmiştir. AmB ile tedavi edilmemiş yani AmB ile hiç karşılaşmamış kökenler in vitro olarak duyarlı bulunmuştur. Bu nedenle AmB'nin C. lusitaniae enfeksiyonlarının tedavisinde kullanılabileceği vurgulanmıştır ${ }^{(4)}$. Aslında böyle bir sonuca ulaşılabilmesi için genişletilmiş klinik çalışmalardan elde edilmiş çok sayıda kökenin test edildiği in vitro çalışmalara gereksinimimiz bulunmaktadır. Çünkü tek başına in vitro sonuçlardan yola çıkarak kesin klinik yargılara varılamaz.

Ülkemizde yapılmış çalışmalarda da kökenler duyarlı bulunmuştur ${ }^{(17-19)}$. Az sayıdaki çalışmada ise birer köken $\mathrm{AmB}$ dirençli bulunmuştur ${ }^{(20,21)}$. In vitro çalışmaların büyük kısmından elde edilen sonuçlara göre C. lusitaniae kökenleri AmB'ye bütünüyle duyarlıdır. Öyle ise $C$. lusitaniae kökenlerinin neden olduğu enfeksiyonlarda AmB kullanımından kaçınılmasının nedeni az sayıdaki klinik yanıtsızlık sunumudur ${ }^{(10,22,23)}$.

AmB direnci ile ilgili olgu sunumlarından birinde direncin kazanılabileceğini düşündürür şekilde tedavi başlangıcında AmB MİK değeri 0.25 $\mu \mathrm{g} / \mathrm{ml}$ iken, tedavi sonrasında bu değerin $1 \mu \mathrm{g} /$ ml'ye yükseldiği belirtilmiştir. Bu direnç kazanan köken aynı zamanda fenotipik olarak da değişmiş, başlangıçta mavi koloni oluştururken, tedavi sonrası mor koloniye değişmiştir ${ }^{(10)}$. Direncin UV ile uyarılabildiğinin gösterilmesi bu klinik bulguyu desteklemektedir ${ }^{(24)}$.

Son yıllarda yapılmış kapsamlı bir çalışmada, 48 saatte MIKK değerlerinin arttığ1, 24 saatte test edilen 71 C. lusitaniae kökeninden 30'unda 1 $\mu \mathrm{g} / \mathrm{ml}, 12$ 'sinde $2 \mu \mathrm{g} / \mathrm{ml}$, geri kalan kökenlerde 
$<1 \mu \mathrm{g} / \mathrm{ml}$ MİK değeri elde edildiği bildirilmiştir. Bu çalışmada, epidemiyolojik "cut off” (ECV) hesaplanmıştır. Bu değer 24 saat için $2 \mu \mathrm{g} / \mathrm{ml}, 48$ saat için $4 \mu \mathrm{g} / \mathrm{ml}$ olarak hesaplanmıştır. ECV değerlerinin mutasyona veya kazanılmış dirence bağlı olarak gelişen "wild type" (WT) olmayan kökenler ile direnç bulunmayan WT kökenleri ayırmada kullanılabileceği bildirilmiştir. Ancak bunun için fazla sayıda köken bulunmalı ve MIK ve "minimum fungicidal consantrasyon" (MFC) değerleri elde edilmiş olmalıdır. Sınır değer olarak bildirilen $2 \mu \mathrm{g} / \mathrm{ml}$ 'nin WT ve nonWT kökenleri ayırmada kullanılabileceği bildirilmiştir. Buna göre MİK değeri $2 \mu \mathrm{g} / \mathrm{ml}$ 'den fazla olan kökenlerin AmB ile tedavi edilmelerinin başarısızlık ile sonuçlanabileceği yorumlanmiştır ${ }^{(25)}$.

Çalışmamızda, sonuçları direnç sınırı $2 \mu \mathrm{g} / \mathrm{ml}$ olarak kabul edilerek yeniden değerlendirdiğimizde, dirençli köken bulunmamıştır. Direnç sınırını $2 \mu \mathrm{g} / \mathrm{ml}$ olarak kullanılması gerektiği başka çalışmalarda da önerilmiştir ${ }^{(26)}$. Zaten Tablo 2'de gösterildiği üzere, E-test ve mikrodilüsyon yöntemi arasındaki uyum açısından her iki test için de $2 \mu \mathrm{g} / \mathrm{ml}$ sınır değeri kabul edilebilir görünmektedir. Yine çalışmamız sonuçlarına göre, CLSI mikrodilüsyon yönteminde sinır değerin $1 \mu \mathrm{g} / \mathrm{ml}$ alındığı koşulda, E-test için sınır değerin $0.38 \mu \mathrm{g} / \mathrm{ml}$ olarak kabul edilmesi önerilmiştir. Yalnızca E-test uygulayarak sonuç bildiren bir laboratuvarda sınır değer olarak 0.38 $\mu \mathrm{g} / \mathrm{ml} \mathrm{kabul}$ edilir ise, referans yöntem ile en yüksek uyum sağlanacak yani en güvenilir sonuçlar verilmiş olacaktır. AmB duyarlılık testi olarak E-test yapılabileceğini bildiren başka çalışmalar bulunmaktadır. Bu çalışmaların bazılarında direnç sınır değeri olarak $0.38 \mu \mathrm{g} / \mathrm{ml}$ önerilmiştir ${ }^{(27)}$.

$\mathrm{Bu}$ çalışma, $C$. lusitaniae kökenlerinin büyük oranda AmB'ye in vitro duyarlılık gösterdiğini, uygun besiyerleri kullanıldığında dirençli kökenlerin ayrılabildiğini göstermiş ve bu nedenler ile in vitro duyarlilik testlerinde AmB'nin de test edilmesinin klinik uygulamaları yönlendirebileceği sonucuna varılmıştır.

\section{KAYNAKLAR}

1. Akova M. Sistemik fungal infeksiyonların tedavisinde amfoterisin B ve liposomal amfoterisin B kullanımı. ANKEM Derg 1993; 7:179-84.

2. Anır G. Amfoterisin B. J Ped Infect Dis 2011; 5(Suppl 1):119-25.

3. Young LY, Hull CM, Heitman J. Disruption of ergosterol biosynthesis confers resistance to amphotericin $\mathrm{B}$ in Candida lusitaniae. Antimicrob Agents Chemother 2003; 47:2717-24 http://dx.doi.org/10.1128/AAC.47.9.2717-2724.2003

4. Singh J, Rimek D, Kappe R. Intrinsic in vitro susceptibility of primary clinical isolates of Aspergillus fumigatus, Aspergillus terreus, Aspergillus nidulans, Candida albicans and Candida lusitaniae against amphotericin B. mycoses 2006; 49:96-103. http://dx.doi.org/10.1111/j.1439-0507.2006.01197.x

5. Zhang J, Silao FGS, Bigol UG, et al. Calcineurin is required for pseudohyphal growth, virulence and drug resistance in Candida lusitaniae. PLoS One 2012; 7:e44192.

http://dx.doi.org/10.1371/journal.pone.0044192

6. Guinet R, Chanas J, Goullier A, Bonnefoy G, Ambroise-Thomas P. Fatal septicemia due to amphotericin B-resistant Candida lusitaniae. J Clin Microbiol 1983; 18:443-4.

7. Pappagianis D, Collins MS, Hector R, Remington J. Development of resistance to amphotericin B in Candida lusitaniae infecting a human. Antimicrob Agents Chemother 1979; 16:123-6. http://dx.doi.org/10.1128/AAC.16.2.123

8. Ernst JE, Yodoi K, Roling EE, Klepser ME. Rates and extents of antifungal activities of amphotericin B, flucytosine, fluconazole, and voriconazole against Candida lusitaniae determined by microdilution, Etest and time-kill methods. Antimicrob Agents Chemother 2002; 46:578-81 http://dx.doi.org/10.1128/AAC.46.2.578-581.2002

9. Peyron F, Favel A, Michel-Nguyen A, Gilly M, Regli P, Bolmström A. Improved detection of amphotericin B-resistant isolates of Candida lusitaniae by $\mathrm{E}$ test. $J$ Clin Microbiol 2001; 39:339-42. http://dx.doi.org/10.1128/JCM.39.1.339-342.2001

10. McClenny NB, Fei H, Baron EJ, et al. Change in colony morphology of Candida lusitaniae in association with development of amphotericin B resistance. Antimicrob Agents Chemother 2002; 46:1325-8. http://dx.doi.org/10.1128/AAC.46.5.1325-1328.2002

11. Clinical Laboratory Standards Institution. Reference method for broth dilution antifungal susceptibility testing of yeasts. Approved standard CLSI document M27-A3. Wayne, Pa: 2008.

12. Alp Ş, Sancak B, Arıkan S. Candida türlerinin amfoterisin B'ye duyarlılığının E test ve iki farklı besiyeri ile önerilmiş olan direnç sınır değerlerine göre araştırılmas1. Mikrobiyol Bul 2008; 42:293-300. 
13. Yücesoy M, Mutlu E, Yuluğ N. Antifungal duyarlılığın saptanmasında E test yönteminin değerlendirilmesi. ANKEM Derg 2001; 15:670-7.

14. Pfaller MA, Andes DR, Diekema DJ, et al. Epidemiology and outcomes of invasive candidiasis due to non-albicans species of Candida in 2,496 patients: data from the Prospective Antifungal Therapy (PATH) registry 2004-2008. PLoS One 2014; 9:e101510. http://dx.doi.org/10.1371/journal.pone.0101510

15. Chan S, Baley ED, Hossain J, Di Pentima MC. Candida species bloodstream infections in hospitalised children: A 10-year experience. J Paediatr Child Health 2015; 51:857-60. http://dx.doi.org/10.1111/jpc.12905

16. Dutta A, Palazzi DL. Candida non-albicans versus Candida albicans fungemia in the non-neonatal pediatric population. Pediatr Infect Dis J 2011; 30:664-8. http://dx.doi.org/10.1097/INF.0b013e318213da0f

17. Kuzucu Ç, Yetkin G, Çalışkan A. Bir yıl içerisinde kan kültürlerinden izole edilen Candida türlerinin dağılımı ve antifungal duyarlılıkları. Erciyes Tip Derg 2007; 29:115-9.

18. Evci C, Ener B, Göral G, Akçağlar S. Comparative evaluation of the antifungal susceptibility of Candida isolates from blood specimens: results of a study in a tertiary care hospital in Bursa, Turkey. Turk J Med Sci 2010; 40:141-9.

19. Keçeli Özcan S, Mutlu B, Dündar D, Willke A. Kan kültürleinden izole edilen Candida spp. suşlarının antifungal ilaçlara karşı duyarlılıklarının belirlenmesinde buyyon mikrodilüsyon ile $\mathrm{E}$ test yöntemlerinin karşılaştırılması. Mikrobiyol Bul 2010; 44:263-71.

20. Amran F, Aziz MN, Ibrahim HM, et al. In vitro antifungal susceptibilities of Candida isolates from patients with invasive candidiasis in Kuala Lumpur hospital, Malaysia. J Med Microbiol 2011; 60:1312-6. http://dx.doi.org/10.1099/jmm.0.027631-0

21. Aydın F, Bayramoğlu G, Güler NC, Kaklıkkaya N, Tosun I. Bloodstream yeast infections in a university hospital in northeast Turkey: a 4 year. Med Mycol 2011; 49:316-9. http://dx.doi.org/10.3109/13693786.2010.512023

22. Merz WG. Candida lusitaniae: frequency of recovery, colonization, infection, and amphotericin B resistance. J Clin Microbiol 1984; 20:1194-5.

23. Blinkhorn RJ,Adelstein D,Spagnuolo PJ.Emergence of a new opportunistic pathogen Candida lusitaniae. $J$ Clin Microbiol 1989; 27:236-40.

24. Yoon SA, Vazquez JA, Steffan PE, Sobel JD, Akins RA. High frequency in vitro reversible switching of Candida lusitaniae clinical isolates from amphotericin B susceptibility to resistance. Antimicrob Agents Chemother 1999; 43:836-45.

25. Pfaller MA, Espinel-Ingroff A, Canton E, et al. Wild type MIC disributions and epidemiological cutoff values for amphoterisin B, flucytosine, and itraconazole and Candida spp. as determined by CLSI broth microdilution. J Clin Microbiol 2012; 50:2040-6. http://dx.doi.org/10.1128/JCM.00248-12

26. Pfaller MA, Diekema DJ. Progress in antifungal susceptibility testing of Candida spp. by use of Clinical and Laboratory Standards Institute Broth Microdilution Methods, 2010 to 2012. J Clin Microbiol 2012; 50:2846-56

http://dx.doi.org/10.1128/JCM.00937-12

27. Favel A, Michel-Nguyen A, Datry A, et al. Susceptibility of clinical isolates of Candida lusitaniae to five systemic antifungal agents. J Antimicrob Chemother 2004; 53:526-9. http://dx.doi.org/10.1093/jac/dkh106 